Informal Logic

\title{
Discovering Warrants in Political Argumentation
}

\section{Irmtraud Gallhofer et Willem Saris}

Volume 41, numéro 4, 2021

URI : https://id.erudit.org/iderudit/1084847ar

DOI : https://doi.org/10.22329/il.v41i4.6765

Aller au sommaire du numéro

\section{Éditeur(s)}

Informal Logic

ISSN

0824-2577 (imprimé)

2293-734X (numérique)

Découvrir la revue

Citer cet article

Gallhofer, I. \& Saris, W. (2021). Discovering Warrants in Political Argumentation. Informal Logic, 41(4), 641-676.

https://doi.org/10.22329/il.v41i4.6765

\section{Résumé de l'article}

Les philosophes nient qu'une proposition d'action puisse être déduite d'arguments pour ou contre cette proposition car ils peuvent être incompatibles. Néanmoins, les gens en général, et les politiciens en particulier, prennent des décisions et présentent des arguments qu'ils jugent convaincants. Nous avons étudié des politiciens qui prenaient des décisions dans des situations complexes. Ils ont parlé des actions possibles, de leurs conséquences, les probabilités de ces conséquences et de leurs évaluations, mais ils ont rarement indiqué pourquoi leurs arguments avaient conduit à leur choix. Nous avons émis l'hypothèse que des règles d'argumentation implicites étaient impliquées et avons vérifié si elles prédisaient ces choix. Nous avons trouvé sept règles de logique non formelle implicites impliquées. Nous avons également trouvé que des personnes dans un échantillon aléatoire ont fait les mêmes choix en se basant sur les mêmes arguments, ce qui suggère des règles d'inférence de base par lesquels les gens discutent des décisions. 


\section{Discovering Warrants in Political Argumentation}

\section{IRMTRAUD GALLHOFER}

\author{
Sociometric Research Foundation \\ 08019 Barcelona \\ Spain \\ irmtraud.gallhofer@gmail.com
}

\section{WILLEM SARIS}

\begin{abstract}
Philosophers deny a proposal for actions can be deduced from arguments for or against the proposal because they may be incompatible. Nevertheless, people in general, and politicians especially, make decisions and present arguments they believe are convincing. We studied politicians who made decisions in complex situations. They spoke about possible actions, their consequences, the probabilities of these consequences and their evaluations, but rarely indicated why their arguments led to their choice. We hypothesized implicit argumentation rules involved and checked whether they predicted those choices. We found seven implicit informal logic rules involved. We also found a random sample of people made the same choices based on the same arguments, suggesting basic warrants by which people argue about decisions.
\end{abstract}

\section{Sociometric Research Foundation 08019 Barcelona Spain w.saris@telefonica.net}

Résumé: Les philosophes nient qu'une proposition d'action puisse être déduite d'arguments pour ou contre cette proposition car ils peuvent être incompatibles. Néanmoins, les gens en général, et les politiciens en particulier, prennent des décisions et présentent des arguments qu'ils jugent convaincants. Nous avons étudié des politiciens qui prenaient des décisions dans des situations complexes. Ils ont parlé des actions possibles, de leurs conséquences, les probabilités de ces conséquences et de leurs évaluations, mais ils ont rarement indiqué pourquoi leurs arguments avaient conduit à leur choix. Nous avons émis l'hypothèse que des règles d'argumentation implicites étaient impliquées et avons vérifié si elles prédisaient ces choix. Nous avons trouvé sept règles de logique non formelle implicites impliquées. Nous avons également trouvé que des personnes dans un échantillon aléatoire ont fait les mêmes choix en se basant sur les mêmes arguments, ce qui suggère des règles d'inférence de base par lesquels les gens discutent des décisions.

Keywords: argumentation rules, data, warrants and claims, strategies, outcomes, utilities and probabilities 


\section{Introduction}

In his publication "Multidimensionality and non-deductiveness in deliberative argumentation" Kock (2017) presents an interesting overview of the history of thinking by philosophers from before Aristotle till now about the possibility to deduce proposals for actions from given possible consequences of these actions. The general conclusion of them and the author is that the multidimensionality of the consequences make the deduction of a choice of action impossible. The reason for this impossibility is that "no logical rules can tell us how to put such heterogeneous arguments on a common denominator and to calculate the net result. They lack commensurability" (p. 108).

Although this description of the problem of argumentation for action is most of the time correct, the reality is that all people, but especially politicians, have to make arguments for actions. In debates of members of governments with each other and with experts they have to determine a course of action. In the debates we have studied, at least some participants try to make arguments to convince the other participants of their choice of action. This suggests that there have to be some rules of argumentation, which they think will work to convince others of their choice of action. How is it possible that the philosophers and some scholars in deliberative argumentation think that one cannot make a convincing argument for actions while politicians think that they are making convincing arguments?

Our study of arguments concerned foreign policy decisions. All the arguments studied were obtained from secret documents of government meetings or expert advice that were only accessible to the participants in the discussions and not accessible to the public at the time of the event. Only thirty years after the event took place were they accessible for research. In order to illustrate what arguments for political actions look like, we present two examples which are compact but complete enough to illustrate such arguments. More examples will be presented later.

The first argument comes from the Governor-General of the Dutch East Indies. They were at that time still a colony of the Netherlands. In 1945, freedom fighters had declared the independent Republic of Indonesia. The Dutch government ignored this declaration 
and wanted to restore its authority in that region. The Dutch Governor-General of the Dutch East Indies asked his government's permission to occupy the seat of the Republic. The copy of his telegram to the government is made available in a publication of Drooglever and Van Schouten (1982, august 4, 1947, no. 149, pp. 223-225). This is the literary translation of the Dutch text:

If we were to do nothing, it is very improbable that the Republic will respect the cease-fire order, but the chance is rather high that a new untenable situation will be created. However, if we occupy the seat of the republican govern it is highly probable that a political reconstruction will be achieved while the risk of creating a new untenable situation is very small.

In his argument, the Governor-General mentioned two possible actions with their consequences and the connected uncertainties. With this argument, he tries to convince the government in the Netherlands of his preferred action. He probably thought that this was a convincing argument, otherwise, we suppose, he would have chosen another argument. Therefore, the question is: why did he think so?

This was a rather simple argument, and the government wrote back to him that they were not convinced, because they were more and more worried about the national and international consequences. Given this reply, the Governor-General was taking these possible consequences also into account in next arguments. For example, on August 26 of the same year, he sent the government a new telegram (Drooglever and Van Schouten, 1982, august 26, 1947, no. 401, 639-640). The translated version is presented below:

If we do nothing, we will be defeated in Indonesia, our international position will not improve and there will be a great increase in the number of victims. If we occupy the seat of the Republican government there will be no defeat in Indonesia, our international position will not deteriorate and there will be no increase in the number of victims.

In this argument, the Governor-General considers the same actions, but now he takes into account the three possible consequences that the government suggested which are incommensurable as 
expected in the literature. Nevertheless, the speaker at least hopes that he makes a convincing argument for the action he prefers.

In our research, we have looked for the implicit argumentation rules which politicians use to convince others of their preferred course of action. We agree with the scholars who have said that in such multidimensional problems a logical deduction seems not possible. Nevertheless, the decision makers draw conclusions based on such arguments. This suggested to us that there must exist informal logical rules that people use to derive preferred actions. Toulmin (1958) has called such a study a "warrant establishing study." So we are looking for the warrants in arguments of politicians who make arguments for their preferred action while other different possible actions with possibly uncertain and incommensurable consequences are also possible.

Below, the first argument mentioned above is represented in the form suggested by Toulmin:

I think that we should occupy the seat of the Republic (Claim)

Because (data)

- if we occupy the seat of the Republic, it is highly probable that a political reconstruction will be achieved, but it also may create an untenable situation.

- If we do nothing it is very improbable that the Republic respects the cease-fire order, but it is more likely that an untenable situation will be created.

The claim should follow from the data. The data consist of two statements about two possible actions and their consequences and uncertainties. In our "Decision Theoretical Approach" (DTA), such an argument is summarized in the following so called "decision tree.” 


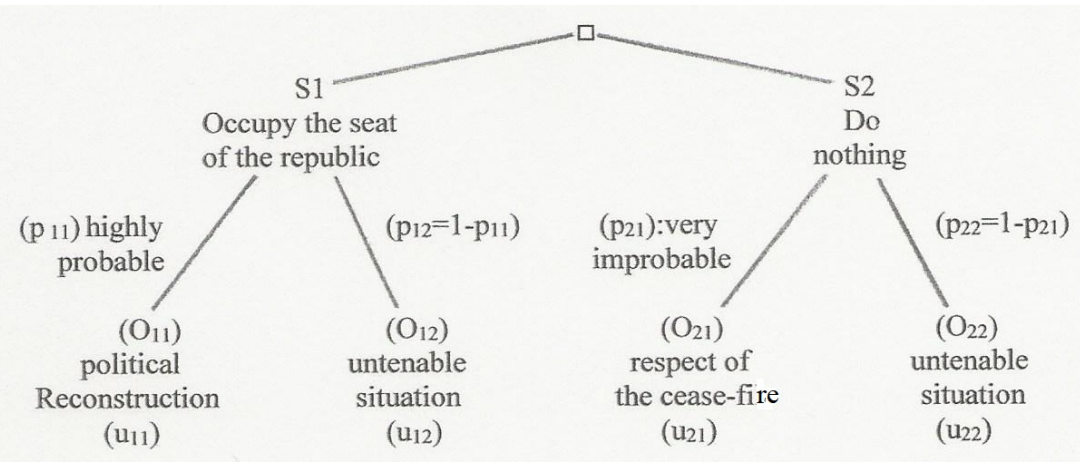

Figure 1. The argument from above presented in a decision tree.

This representation clearly shows the components, which play a role in this argument: two possible actions (strategies denoted by $\mathrm{S} 1$ and $\mathrm{S} 2)$, outcomes $\left(\mathrm{O}_{\mathrm{ij}}\right)$ with their probabilities $\left(\mathrm{p}_{\mathrm{ij}}\right)$ and utilities $\left(\mathrm{u}_{\mathrm{ij}}\right)$. In this case the strategies and the outcomes are explicitly mentioned, the probabilities are only partly specified in words ( $\mathrm{p}_{11}$ and $\mathrm{p}_{21}$ ) but not their complements. Finally, the utilities, the evaluations of the outcomes, are not mentioned but implied by the connotation of the words used to specify the outcomes: "political reconstruction" is definitely positive as well as "respect of the cease-fire" while "untenable situation" is clearly negative. However, the sizes of these positive and negative evaluations are not specified.

\subsection{Mathematical decision theory}

Most foreign policy decisions involve multiple consequences for each available strategy (e.g., on the national and international level, in the short and the long-term, concerning public opinion in relevant countries, etc). These consequences can be neutral, positive or negative. In addition, they can vary in uncertainty.

For these so-called "multi-attribute utility problems under uncertainty," decision theory (Fishburn, 1964; Keeney and Raiffa, 1976) has developed a mathematical approach to derive optimal choices. One of them is the "Subjective Expected Utility rule" which states:

One must choose the strategy with the maximal Subjective Expected Utility (SEU). 
The SEU is the weighted average of the utilities of the outcomes for each strategy. The probabilities of the different outcomes are used as the weights. This leads to the following formula for the strategies 1 and 2 of the example presented in Figure 1.

The SEU for strategy $S 1=p_{11} u_{11}+p_{12} u_{12}$

The SEU for strategy $\mathrm{S} 2=\mathrm{p}_{21} \mathrm{u}_{21}+\mathrm{p}_{22} \mathrm{u}_{22}$

When the SEU, is computed for all strategies, the strategy with the highest overall utility, SEU, should be chosen.

Using Toulmin's (1958) terminology, the specification of the strategies and the outcomes, utilities and probabilities are the "data," the SEU rule is "the warrant," and the choice of the best strategy is "the claim." This mathematical approach assumes that the utilities of the consequences can be added. This is questionable if the consequences are as incomparable as in political decision problems as we have shown before.

Nevertheless, in our first study (Saris and Gallhofer, 1975), using this approach, we quantified all probability and utility statements of the decision makers. By applying the SEU rule we predicted the choice the decision makers had made. ${ }^{1}$ Afterwards it became clear to us that this approach required too many questionable assumptions besides the commensurability of the consequences. In general, the members of the government neither have this type of numeric information nor use this formal approach to determine their choice of action. However, it is very clear from the minutes that they approximate this approach by specifying possible strategies and possible consequences including the probabilities and utilities. Since the

\footnotetext{
${ }^{1}$ In this study of arguments of decision makers (Charles V and Margret of Austria) we quantified the expressions of probabilities and utilities mentioned in the text, using scaling procedures from the social sciences, and applied the SEU rule to see whether we could derive the same conclusion as the decision makers. That was indeed the case as we showed in Saris and Gallhofer (1975). Looking at more minutes of arguments about decisions, we realized that we overestimated the quantitative characteristics of such processes, which led to the conclusion that the SEU decision rule could not be applied. Therefore, we started to look for alternatives.
} 
SEU rule can't be applied, we have to look for alternative approaches for rules for argumentation concerning actions.

\subsection{Pragmatic argumentation}

In the documents we have studied about political decisions by members of the government, there are always two or more possible actions mentioned. However, if the government has made a decision, a document will be sent to the parliament where they mention the chosen action and the reason why they have chosen this action. For example, in this specific case, the parliament would get the following text:

The government has decided that we should occupy the seat of the Republic

because

if we occupy the seat of the Republic, it is highly probably that the political reconstruction will be achieved.

These two sentences constitute an instance of "pragmatic argumentation" (Perelman, 1959):

$\mathrm{X}$ must be done

$\mathrm{X}$ highly probably leads to a positive result $\mathrm{Y}$.

van Eemeren and Grootendorst (1984), van Eemeren, Garssen and Meuffels (2009), Andone (2014), van Eemeren (2016), and Andone and Lomeli Hernandez (2019) discuss under what conditions such an argument should be acceptable. Several criteria for acceptability have been mentioned such as: that X leads to Y, Y must indeed be positive and $\mathrm{X}$ should not have negative side effects that most people would accept result $\mathrm{Y}$ and that $\mathrm{Y}$ is more desirable than other possible results. These points are indeed very relevant to determine the acceptability of such arguments. The evaluation of such arguments in the parliament is very well described and analyzed in the papers of Andone (2014), and Andone and Lomeli Hernández (2019). 
However, we have not studied public debates in this phase of the decision making process, instead we studied, on the basis of partially secret documents and minutes of meetings of decision makers, the earlier non-public phase of the decision process. In this phase, the ministers and experts on the topic discuss the different options that are available for the given problem. In the previous mentioned papers, alternative options are also mentioned but not with equal attention.

\subsection{Political discourse analysis}

Fairclough and Fairclough (2012) and Lewiński (2017) discuss the situation that two or more alternatives are compared as was the case in the above examples. According to Fairclough and Fairclough (2012, p. 57), agreeing with Blair (2016), one has not only to look at the logical aspects of the arguments but also the rhetorical and dialectical aspects. They argue that it is not enough to look at the fact whether the argument is logically justified. One also has to consider the convincing power with respect to the audience and the amount of attention given to opposing opinions. They suggest a claim like the first statement in the example but on the basis of much more information. They consider the "goal" of the decision maker and the "means" to realize this goal. They consider "other means" for that goal and "negative side effects" of the possible means and "values." They also consider information about "circumstances" to be taken into account. There is a big difference in the way the politicians present their point of view in the studies of Fairlough and Fairlough and our studies. Their empirical examples are speeches of politicians in the parliament or in other public meetings. There they have to indicate clearly their goals and the means to realize these goals and the possible side effects.

In the empirical examples we will describe in this paper, we have not seen that politicians specify the goal of their action. In these situations, all participants knew what the goals were. Therefore, the speakers concentrate on possible actions, their consequences, and uncertainties expressed in statements about the likelihood of the consequences. This information hardly plays a role in the discourse analysis. 


\subsection{Practical reasoning arguments: Modular approach}

Macagno and Walton published in 2018 a paper about an alternative approach for looking at argumentations of politicians. Below we present a text, which was used to explain how the modular approach they suggested works. Looking at this text, it will be clear that they deal with very different texts than we have studied. They used a text, which indicates how Putin thinks about cooperation with the Syrian government (Macagno and Walton 2018, p. 539).

Mr. Putin said it was "an enormous mistake to refuse to cooperate with the Syrian government and its armed forces, who are valiantly fighting terrorism face to face" conveniently ignoring the fact that Mr. Assad's main target has always been his domestic opposition, not the Islamic State. He portrayed Mr Assad as a force for stability and said the only solution "is to restore their statehood where it has been destroyed,"

This text does not represent an argument of a politician about a possible action that he prefers next to other possible actions with different possible consequences and probabilities. It is rather a reconstruction of a decision of a politician in a public speech. In this speech he justifies his choice of action. Therefore, the emphasis is on the chosen option to support Mr. Assad "to restore their statehood" where it has been destroyed by domestic opposition. Of the alternative, "to refuse to cooperate with the Syrian government" is only said that it was "an enormous mistake." This is a rather different type of argument then we have studied.

\subsection{Decision theoretical approach}

We have seen that the arguments differ depending on the situation in which they are presented. Only in the internal meetings of government members do arguments concentrate on possible actions, their consequences, their probabilities and utilities. Therefore, we decided to continue with DTA to detect the informal logic rules of these arguments for action.

Much has been published about the formulation of arguments, but for us the most relevant approach is the one described by Toulmin (1958) and his successors including Erduran, Simon and 
Osborne (2004), Garcia-Milla, Gilabert, Erduran and Felton (2013), Bermejo-Luque (2004, 2019). Toulmin (1958, p. 120) mentions two approaches to argumentation research. The first he calls "warrant using" and the second "warrant establishing." Our first DTA study was a warrant using study. Later, we doubted this approach in political decision making, and therefore, we planned a "warrant establishing" research project with respect to political arguments for preferred actions.

In this study we proceed as follows. In section 2, we provide examples of different types of arguments on the basis of the information about probabilities and utilities which we have detected in our research. In section 3, we will specify hypotheses concerning the warrants for the different types of arguments. In section 4, we present the methodology used to test these hypotheses which consists of three steps: 4.1. Drawing a representative sample of decisions situations to study the arguments used. 4.2. Determining whether the warrants we suggested for the different arguments indeed predict the actual choices. 4.3. Testing if non-politicians also know these warrants. In section 5, we discuss to what extent these results can be generalized across countries and decision makers. In the last section, we present the conclusions and limitations of this research.

\section{Arguments that underlie decisions}

In the previous section we have mentioned that utilities and probabilities must play an important role in the process of selecting a strategy from a set of possible strategies. It was not indicated how this can be done if no numeric values are used. The basic structure of the argument by the governor in the previous section can be presented as follows: 


\section{Example 1}

S1 must be done (claim)

Because (data)

S1 will lead with high probability to the positive result $\mathrm{A}$, but it may also lead to the negative result B

S2 very unlikely will lead to the positive result $C$, but the negative result $\mathrm{B}$ is more likely.

In this argument, the likelihood of the different probabilities is specified using terms "highly probably", "very unlikely" and "more likely". Such probabilities are called ordinal or rank-ordered (Stevens, 1946).

In this case the utilities can only be derived on the basis of the connotation of the used terms "political reconstruction," "untenable situation," and "that the Republic respects the cease-fire." All readers of the document of course knew that the first outcome (A) was positive, the second (B) negative and the third (C) positive, but they had no information on the relative utility of these consequences according to the decision maker. When the relative size of the utilities of the different consequences is not indicated, the utilities are called "nominal" or "without rank- order" (Stevens, 1946).

In this example, the utilities are nominal and the probabilities are ordinal; therefore, this is an argument with nominal utilities and rank-ordered probabilities. The rank-ordering of the probabilities must have been done for a reason; therefore, we suppose that this rank-order must play a role in deriving the claim. ${ }^{2}$

The same decision maker formulated a different argument for the same situation at an earlier point in time. The argument was formulated as follows:

${ }^{2}$ If one ignores the ordered probabilities the propositions of the data reduce to: $\mathrm{S} 1$ will lead to the positive result A, but it may also lead to the negative result $\mathrm{B}$, while $\mathrm{S} 2$ will lead to the positive result $\mathrm{C}$ but also to the negative result $\mathrm{B}$. In this case, there is no way to choose between $\mathrm{S} 1$ and $\mathrm{S} 2$. This means that it seems that the choice must have been determined by the specified probabilities. 
I think that we should occupy the seat of the Republic because

- if we occupy the seat of the Republic, the Republic may capitulate or be liquidated completely.

- If we do nothing it is possible that the Republic capitulates, but it is also possible that our position in the East Indies will not improve.

The formal structure can be presented as follows:

\section{Example 2}

S1 must be done (claim)

Because (data)

S1 may lead to a positive result A or a positive result B

S2 may lead to a positive result $A$ or to the negative result $C$

In this formulation of the argument, neither the probabilities nor the utilities are rank ordered, as such, it represents an argument with nominal utilities and nominal probabilities. When so little information is provided, it is even more curious which "obvious warrant" suggests choosing the first strategy, as the decision maker seems to think. Given the lack of rank-ordering of the probabilities the warrant for this type of argument should be different from the warrant for the first argument where rank ordering was used. There are also arguments which are called "arguments with ordinal utilities and nominal probabilities." We will give an example of such an argument below.

The government told the governor that he failed to address the consequences on the international and national level. America threatened to stop the Marshall help if the Dutch government continued the war in Indonesia. Moreover, there was more opposition among the Dutch population against this so-called "police action." Given these remarks, the governor sent a new telegram to The Hague with the following argument: 
I think that we should occupy the seat of the Republic because

- if we occupy the seat of the Republic, it will not lead to our defeat in Indonesia but there will be international and national troubles which would be very serious

- If we do nothing it will lead to our defeat in Indonesia but not to international and national problems. Defeat in Indonesia would be the worst outcome I can imagine.

- The Indonesian question is, in my opinion primary, not ancillary.

In addition to the consequences of the two strategies the Governor also mentions his rank ordering of the evaluations (utilities) of the different consequences. Here we see that the Governor explicitly orders the different consequences according to their utilities. On the other hand, he doesn't pay any attention to the probabilities. This argument is an example of "an argument with ordinal utilities and nominal probabilities". The structure of this argument can be specified as follows:

\section{Example 3}

S1 must be done (claim)

Because (data)

S1 will lead to the very advantageous result $\mathrm{A}$ but also to the very serious results $\mathrm{B}$ and $\mathrm{C}$

S2 will lead to the worst result not-A but not to the very serious results $\mathrm{B}$ and $\mathrm{C}$.

In this case, it seems difficult to decide between $\mathrm{S} 1$ which leads to one very positive result and two negative ones and S2 which leads to one very negative consequence, but also two positive ones. How the governor came to his conclusion (S1) we will clarify later. We suppose that the ordered utilities should play a role in the warrant, otherwise he would not have paid so much attention to these aspects of the argument. Therefore, for this kind of argument we expect again different warrants. 
Finally, the decision makers may provide rank-ordered information about both the probabilities and the utilities of the different consequences. A relatively simple example is the argument made by the Hungarian Prime minister, in 1914, after the assassination in Serbia of the Austro-Hungarian heir for the throne. ${ }^{3}$ Figure 2 presents an example of such an argument. The structure of this argument is presented below

\section{Example 4}

S2 must be done (claim)

Because (data)

S1 may lead with high probability to the negative result A, but may also lead with a very small probability to the positive result $\mathrm{B}$

S2 may lead with high probability to the positive result $C$ but also with a very small probability to the negative result $\mathrm{D}$, which is less negative than result A.

In this argument with rank ordering of utilities and probabilities it is even more difficult to formulate the warrant which leads to the conclusion of the decision maker. This warrant should make use of the ordering of the utilities and probabilities as with the SEU rule unless the argument has a very special simplified structure that allows a simpler rule to indicate the conclusion.

${ }^{3}$ This is table 4.2 in Gallhofer and Saris (1996) 


\begin{tabular}{|c|c|c|c|c|}
\hline Strategies & & Outcomes & & \\
\hline & $\begin{array}{l}\text { O11 } \\
\text { The Balkan states become } \\
\text { our enemies with the } \\
\text { exception of Bulgaria, } \\
\text { which cannot help us, and } \\
\text { we enter a fight for life and } \\
\text { death with Russia }\end{array}$ & $\begin{array}{l}\mathrm{O}_{12} \\
\text { The Balkan } \\
\text { states do not } \\
\text { become our } \\
\text { enemies and } \\
\text { we do not } \\
\text { enter a fight } \\
\text { for life and } \\
\text { death with } \\
\text { Russia }\end{array}$ & $\begin{array}{l}\mathrm{O}_{21} \\
\text { Our } \\
\text { demands are } \\
\text { accepted, } \\
\text { which leads } \\
\text { to a } \\
\text { diplomatic } \\
\text { success with } \\
\text { the } \\
\text { restoration } \\
\text { of our } \\
\text { prestige in } \\
\text { the Balkans } \\
\text { and the } \\
\text { humiliation } \\
\text { of Serbia, } \\
\text { improving } \\
\text { our position }\end{array}$ & $\begin{array}{l}\text { Osz } \\
\text { Our } \\
\text { demands are } \\
\text { not } \\
\text { accepted, } \\
\text { but no fight } \\
\text { for life and } \\
\text { death }\end{array}$ \\
\hline $\begin{array}{l}\text { S1: } \\
\text { Immediately } \\
\text { declare war on } \\
\text { Serbia }\end{array}$ & $\begin{array}{l}\mathrm{U}\left(\mathrm{O}_{11}\right)= \\
\mathrm{P}=\text { highly probably }\end{array}$ & $\begin{array}{l}\mathrm{U}\left(\mathrm{O}_{12}\right)=+ \\
\mathrm{P}=\text { very } \\
\text { small }\end{array}$ & & \\
\hline $\begin{array}{l}\text { S2*: } \\
\text { Deliver an } \\
\text { ultimatum to } \\
\text { Serbia, with heavy } \\
\text { but feasible } \\
\text { demands, and if it } \\
\text { does not accept } \\
\text { them, initiate the } \\
\text { war but without the } \\
\text { aim to destroy } \\
\text { Serbia entirely }\end{array}$ & & & $\begin{array}{l}\mathrm{U}\left(\mathrm{O}_{21}\right)=+ \\
\mathrm{P}=\text { highly } \\
\text { probable }\end{array}$ & $\begin{array}{l}\mathrm{U}\left(\mathrm{O}_{22}\right)= \\
\text { less negative } \\
\mathrm{p}=\text { very } \\
\text { small }\end{array}$ \\
\hline
\end{tabular}

Symbols: $\mathrm{S}_{i}$ strategy i. $\mathrm{S}_{i}{ }^{*}$ chosen strategy. $\mathrm{O}_{i j}$ outcome j under strategy i. L $\left(\mathrm{O}_{i j}\right)$ utility of outcome j under strategy i. P probability of outcome. Cells that are empty for specific strategy were not considered by the decision-maker.

Figure 2. Table 4.2 in Gallhofer and Saris (1996). 
Based on the information provided with respect to utilities and probabilities four different types of arguments have been formulated:

1. Arguments with nominal utilities and probabilities.

2. Arguments with nominal utilities and rank-ordered probabilities.

3. Arguments with rank-ordered utilities and nominal probabilities.

4. Arguments with rank-ordered utilities and rank-ordered probabilities.

We expected that each type of argument would require different warrants. Therefore, we specified hypotheses about the warrants for the four different types of data identified that should be so obvious that decision makers think that they don't have to mention them.

\section{Hypotheses concerning the warrants for the different forms of arguments}

Given that the information about the utilities and probabilities provided in the problem descriptions (data) is limited, the question arose as to how the choices can be derived from these descriptions of the decision problems? This issue is challenging because the politicians hardly ever specified these rules. In seeking warrants that were specific to the different types of arguments, we assumed that the rules should use the information given in the description. For example, if utilities are specified with rank-order then the rule should use this information. The same applies if probabilities are presented with rank-order and when both are rank ordered. This basic assumption led us to develop warrants for each class of arguments separately. Given that there are four different ways arguments are formulated we expected at least four different types of warrants, but it turned out that in some classes more warrants could be formulated. 


\subsection{Warrants for Type 1: Arguments with nominal utilities and probabilities}

The warrants for this type of arguments should provide a decision without any rank-ordered information. In this class we specified two rules inspired by the work of the Nobel Prize winner Herbert Simon (1957). Simon suggested that people do not evaluate all available strategies before making a choice, they select the first strategy that provides a satisfactory result. We could not use the sequential aspect of this rule but concentrated on the satisficing aspect. In doing so, we specified two rules. We called them the Simon rule and the Reversed Simon rule. They are formulated as follows (Gallhofer and Saris, 1996).

\section{The Simon rule}

If the outcomes of one strategy are all positive while for the other strategies at least one of the outcomes is negative then the strategy with only positive outcomes should be chosen.

The idea behind the rule is that one chooses the strategy that certainly leads to a positive result.

\section{The Reversed Simon rule}

If for one strategy at least one positive outcome is possible while for all other strategies only negative outcomes are expected, the strategy which can lead to a positive result should be chosen.

The idea behind this rule is that one avoids that the choice certainly would lead to a negative result because the other strategy provides at least a chance of a positive result. We could not think of other rules for this type of arguments, though we can imagine many different situations with more complex data where these rules can't be applied. Example 2 clearly illustrates that the Simon rule (warrant) suggests the chosen strategy. 
3.2. Warrants for Type 2: Arguments with nominal utilities and rank-ordered probabilities

We thought that the warrants for this type of argument should take the rank-ordering of the probabilities into account (Gallhofer and Saris, 1996). We considered two rules: a positive and negative Risk Avoiding rule.

\section{The positive Risk Avoiding rule}

If the probability of a positive result is greater for one strategy than for any other strategy, the former strategy has to be chosen.

The idea behind this rule is that one chooses the strategy with the highest chance of a positive result.

\section{The negative Risk Avoiding rule}

If the probability of a negative result is smaller for one strategy than for any other strategy, the former strategy has to be chosen.

The idea behind this rule is that one chooses the strategy with the lowest chance of a negative result. We could not think of other rules for this type of arguments. However, it is not difficult to specify decision problems in this class that can't be solved by these two rules. The positive Risk Avoiding rule (warrant) predicts the chosen strategy in Example 1.

\subsection{Warrants for Type 3: Arguments with rank-ordered utilities and nominal probabilities}

These warrants should be based on the rank-order of the utilities. Four decision rules are known for this type of arguments. The first is the Dominance rule (Montgomery, 1989), the second is the Minimax theory (Savage, 1954), The third is the Lexicographic rule (Thrall, Coombs and Davis, 1954) and the fourth is the Addition of Utilities rules (Fishburn, 1964). 


\section{The Dominance rule}

If one strategy is better concerning at least one consequence and equally good in all other consequences compared with the other strategies, the former strategy has to be chosen.

The idea behind this rule is that one should choose the strategy that provides a better or equally good outcome as all other strategies. The Dominance rule clarifies the choice of the strategy in the second example in the introduction.

\section{The Minimax rule}

If for one strategy the worst outcome is better than the worst outcome for any other strategy then the former strategy has to be chosen.

The idea behind this rule is that one should choose the strategy that leads to an outcome that is not worse than for all other strategies

\section{The Lexicographic rule}

If one strategy is better on the most important aspect of the decision problem than the other strategies, the former one has to be chosen.

The idea behind this rule is that one chooses the strategy that leads at least to a better result than all other strategies on the most important consequence. The Lexicographic rule suggest the choice of the strategy in the example 3.

\section{The Addition of Utilities rule}

If the sum of the utilities of the consequences of one strategy is better than the sum of the utilities of the consequences of the other strategies the former strategy has to be chosen.

The idea behind this rule is that one chooses the strategy that leads to the highest utility across all possible consequences. This is a rule that ignores the problem of lack of commensurability of the outcomes by suggesting to take the sum over the possible 
outcomes to determine the total utility of a strategy. If that is done this problem is reduced to a decision problem of the type 1 .

The application of the last two rules requires that the decision maker specifies next to the decision problem also further information about the importance of the consequences or the ranking of the sums of the utilities of all consequences together for all strategies.

Although we have specified four different warrants it is not so difficult to create different structures of decision problems that don't fit any of the decision problems mentioned here.

In Example 3, the decision maker has mentioned that the first consequence, the result in Indonesia, is the most important one. As such, his choice follows from the given information using the Lexicographic rule (warrant).

\subsection{Warrants for the Type 4: Arguments with rank-ordered utilities and rank-ordered probabilities}

In this case the information about utilities and probabilities will generally require the numeric SEU rule to provide a solution. In Example 4 the second strategy has a much higher probability to a positive result than the first strategy while the possible negative result of the second strategy is less negative than the negative result of the first strategy and has also a smaller probability to occur under the second strategy. In this very specific situation, choosing the second strategy is reasonable. Usually, in these cases, it is hard to draw conclusions on the basis of non-numeric data.

All these rules may serve as warrants in the sense that they are the link between the data and the claim as suggested by Toulmin (1958) and Bermejo-Luque (2004). In contrast with other potential warrants, these are based solely on formal characteristics (probabilities and utilities) of the sentences about the data and not on any of the substantive aspects mentioned. Therefore, these warrants are applicable to any argument in the specific class. This is another interesting requirement that has been suggested by Bermejo-Luque (2019). 


\section{The methodology used to test these hypothesized warrants}

The hypothesized warrants were tested in three steps. The first step (section 4.1) involved collecting sufficient data on arguments for decisions. The selection of arguments should also be representative for the arguments that occur in practise. On the other hand, the procedure should be practical. Based on these criteria, we designed a study in our home country (The Netherlands). We decided to draw a sample of important decision situations reported in historical texts. A random sample was drawn because we didn't want to influence the choice of the decision problems. Otherwise there would be the risk of selecting texts that were in agreement with our hypotheses. In total, 136 decision situations had been chosen and these contained 231 complete arguments of members of the government or their advisors. These 231 arguments were analysed using the procedure we had developed. In this way we determined how the arguments looked like and to which of the four mentioned types of arguments they belonged, according to their utilities and probabilities. We also obtained outcome information, i.e., which strategy was preferred by the decision maker.

The next step (section 4.2) in the process was to check whether one of the hypothesized warrants, which we expected to predict the preferred strategy for the arguments of the different types, indeed predicted the preferred strategy. If this were the case, it would not guarantee that we had found the proper warrants used by the decision makers. Therefore, we liked to do one more test.

Ideally, we would have liked to ask the decision makers directly whether they had in mind the expected warrant when they specified their argument for the preferred strategy. However, many of these decision makers had already died while others were still active in politics; as such, this approach was not feasible. Therefore, we decided to present some of the arguments we observed in our study to a small random sample of the Dutch population. If these warrants are so obvious that they don't require mentioning, anyone who hears the arguments should also be able to identify them. This was tested in two ways: first we asked the selected people to indicate for each decision problem which strategy they thought would be the best. These choices should agree with those made by the decision makers. Next, we asked them to explain how they came to this conclusion. 
Specifically, we asked them to specify in their way the warrant that they applied. A coding procedure we had developed for this purpose, was used to determine if the warrant they specified agreed with the expected warrant or not. This study is reported in section 4.3.

We thought that we could thereby determine maximally in how far our hypotheses with respect to the warrants for the different types of arguments generate the same choice as the decision maker suggested. We could see whether ordinary people would draw the same conclusion on a subset of these arguments and finally whether these people also have a basic understanding of these warrants. The results of these three steps are presented and discussed below.

\subsection{Study of a sample of decision arguments of the Dutch govern- ment}

We drew a sample of 136 of the Dutch government's decision problems concerning foreign policy ${ }^{4}$ in the $20^{\text {th }}$ century, between 1900 and 1955 to determine which arguments justify these decisions ${ }^{5}$. In total 231 arguments of individual decision makers were analysed. Based on decision theory, the texts were coded according to: available strategies, possible consequences, and information about probabilities and utilities.

Often other aspects are mentioned in the texts such as backing of an expectation or the likelihood of an event and criticism of arguments of other speakers. The previous mentioned papers on pragmatic argumentation suggest such remarks (van Eemeren and Grootendorst (1984), van Eeemeren, Garssen and Meuffels (2009), Andone (2014), van Eemeren (2016) and Andone and Lomeli Hernandez (2019)). Similar remarks can also be found in papers of Erduran et al. on argumentation based on Toulmin's model, for

\footnotetext{
${ }^{4}$ At that time rational choice theory was very popular in the social sciences (Becker 1976). We thought that this theory should apply to foreign policy decisions, if it would apply anywhere, given the serious consequences of such decisions.

${ }^{5}$ This research was started in 1985 . Due to the fact that one is only allowed access to minutes after 30 years, the most recent documents that could be studied were from 1955. All selected documents have been exactly documented in the book of Gallhofer and Saris (1996).
} 
example, the paper of Garcia-Milla, Gilabert, Erduran and Felton (2013). Erduran, Simon and Osborne (2004) also developed a coding scheme for these remarks.

In our research, we ignored these elements to concentrate only on the basic structure of the complete argument of each decision maker. A method of detecting such arguments in documents has been developed by Gallhofer and Saris (1996, Appendix A). The quality of the coding has been evaluated by asking several researchers to code the same text and determining the similarity of their results. We started to use the coding procedure once we had found a procedure that was highly reliable across coders.

Based on this research we classified the observed arguments in the four types of arguments mentioned before. In Table 1, the descriptions of the decision problems are classified according to the amount of information on the utilities and probabilities. The table shows that most politicians $(\mathrm{n}=109)$ indicated the possible consequences, without the rank ordering of utilities and probabilities as in the second example presented above. Otherwise, they frequently used either rank-ordered probabilities $(n=70)$ as in Example 1 or rank-ordered utilities $(n=49)$ as in Example 3, but rarely were both rank ordered $(n=3)$ as in example 4 .

Table 1: The description of the consequences of available strategies with respect to the detail of the specification of the utilities and probabilities for the 231 studied cases.

Type of argument

frequency (n)

1. Arguments with nominal utilities and probabilities

2. Arguments with nominal utilities and rank ordered probabilities

3. Arguments with rank ordered utilities and nominal probabilities

4. Arguments with rank ordered utilities and rank ordered probabilities

Since most foreign policy decision problems are problems with uncertain multiple consequences Table 1 indicates that politicians considerably simplify the decision problems. This is done by omitting many aspects and ignoring differences in utilities or probabilities between different consequences, or even in both characteristics 
of the consequences. The decision maker does so to make the oral or written argument more manageable and not too complicated for his audience.

\subsection{Do the hypothesized warrants predict the choices?}

A minimal requirement to accept these rules as the warrants of these arguments is that the hypothesized warrants correctly predict the choice (claim) based on the description of the decision problem (data) presented by the decision maker. Table 2 shows that in $97 \%$ of the cases one of the predicted rules (warrants) correctly produced the proposed choices. The data in this table indicate that these rules are likely the warrants that the decision makers and the listeners apply to derive conclusions. However, this strong relationship is not a proof because the decision makers do not specify which rule they used.

Table 2: The prediction quality of the expected decision rules given the problem description

\begin{tabular}{llccc}
\hline $\begin{array}{l}\text { Information about } \\
\text { utilities and } \\
\text { probabilities }\end{array}$ & $\begin{array}{l}\text { predicted } \\
\text { decision } \\
\text { rule }\end{array}$ & Correct prediction & wrong prediction & total \\
\hline $\begin{array}{l}\text { Utilities and } \\
\text { probabilities } \\
\text { nominal }\end{array}$ & $\begin{array}{l}\text { Simon, } \\
\text { Reversed } \\
\text { Simon }\end{array}$ & 103 & 6 & 109 \\
$\begin{array}{l}\text { Utilities nominal } \\
\text { probabilities } \\
\text { rank ordered }\end{array}$ & $\begin{array}{l}\text { Risk Avoi- } \\
\text { dance rules }\end{array}$ & 68 & 2 & 70 \\
$\begin{array}{l}\text { Utilities rank } \\
\text { ordered, proba- } \\
\text { bilities nominal }\end{array}$ & $\begin{array}{l}\text { Lexicographic } \\
\text { Addition of } \\
\text { utilities }\end{array}$ & 46 & 3 & 49 \\
$\begin{array}{l}\text { Utilities and } \\
\text { probabilities } \\
\text { rank ordered }\end{array}$ & SEU & 2 & 1 & 3 \\
\hline Total & & 219 & 12 & 231 \\
\hline
\end{tabular}

This is a surprising result because one would say that the strategies discussed have often many different consequences with different utilities and probabilities. Nevertheless, the arguments seem to be formulated in such a way that the hypothesized simple rules can 
be applied and therefore, the warrants don't have to be mentioned. To realize that, the decision makers considerably simplify the decision problems to present an argument that the listeners immediately understand at least if they also know these rules.

Interestingly, the Minimax rule has not been found to predict any of the decision makers' claims. This may have to do with the complexity of this rule. Probably this rule is not known by the decision makers while the others are simple enough to be known.

\subsection{Are these warrants generally known?}

We next investigated whether these warrants were known by the audiences of such speeches, which led to the following research questions:

1. Do listeners to such arguments indeed make the same choice as the speakers?

2. Can we show that the listeners indeed apply the expected decision rule?

3. Does the ability to correctly apply these rules vary according to age and education?

Since we did not expect politicians to participate in such a study, we asked a small random sample $(n=59)$ of the Dutch population to participate in this study. These people varied in age $(21 \%$ was younger than 20 years, $39 \%$ between 20 and 40, 29\% between 40 and 60 and $11 \%$ above 65 years old ) and education level ( $25 \%$ had only primary education, $47 \%$ had secondary education and $28 \%$ received higher education). Approximately the same number of men (51\%) and women (49\%) participated in the experiment.

After some explanation and some trials, the participants were presented 13 different decision problems derived from the larger study of real-life arguments about decisions. The selected decision problems have been documented in chapter 8 of Gallhofer and Saris (1996). In this study we presented only the formal structure of the 
argument to prevent biased responses due to the specific context of the argument ${ }^{6}$. A typical specification would be:

Strategy 1 leads with certainty to outcome A. Outcome A is negative.

Strategy 2 probably leads to outcome B. Outcome B is positive. But there is also a very small probability that outcome $\mathrm{C}$ will occur. Outcome $\mathrm{C}$ is negative.

Given such descriptions of the decision problems, the respondents were asked to choose between the specified strategies. The respondents have chosen in $100 \%$ of the cases the strategy that was chosen by the decision maker who specified this argument in the first place in the real-life situation.

Immediately after they had made their choice, we asked the respondents to indicate why they had chosen this strategy. In other words, we asked the respondents to specify the decision rule (warrant) they applied. This procedure is suggested by Ericson and Simon (1984). To detect the rules the respondents specified, a highly reliable coding procedure was developed (Gallhofer and Saris, 1996, Appendix C). The most important results of the second part of the study are summarized in Table 3.

In the experiment, six type 1 decision problems with no ordering of utilities and probabilities were chosen. As such, we received 354 answers (6 times 59 answers, see the last column). Additionally, five type 2 and two type 3 decision problems were chosen. For each type of argument, we determined how many of the rules suggested by the 59 respondents agreed with our hypothesized warrants for that type of argument (column 1). Column 2 provides the percentage of correct specified rules given the total number of answers.

The data presented in Table 3 indicates that people know very well the rules for the simple arguments with nominal utilities and probabilities. Among the cases with nominal utilities and rank

\footnotetext{
${ }^{6}$ If the A, B and C were substituted by real life information, for example, about the decisions of the Dutch government concerning Indonesia, some people were inclined to introduce their own information about these historical events which changed the decision problem and consequently also the rule they would specify.
} 
ordered probabilities, one experiment seems to have been problematic. Without this argument the percentage correct rules would also have been $91 \%$. The argument in question was formulated as follows:

Strategy 1 probably leads to outcome A, A is positive. There is also a small chance that $\mathrm{B}$ will occur. $\mathrm{B}$ is negative.

Strategy 2 probably leads to outcome C, C is negative. There is also a small chance that $\mathrm{D}$ will occur. $\mathrm{D}$ is positive.

Some of the participants wrote down "Because A is better than D". In that case, the answer was coded as incorrect because the probability was not mentioned even though their choice was correct.

Table 3: The number of rules mentioned that were acceptable to choose a preferred strategy for different types of arguments

\begin{tabular}{llll}
$\begin{array}{l}\text { Information about } \\
\text { Utilities and } \\
\text { Probabilities }\end{array}$ & $\begin{array}{l}\text { rule mentioned } \\
\text { acceptable } \\
\text { (n) }\end{array}$ & $\begin{array}{l}\text { rule mentioned } \\
\text { accptable } \\
(\%)\end{array}$ & $\begin{array}{l}\text { total number of answers } \\
\text { arguments x participants }=\end{array}$ \\
\hline $\begin{array}{l}\text { Utilities and } \\
\text { Probabilities }\end{array}$ & & & \\
$\begin{array}{l}\text { Nominal } \\
\text { Utilities nominal }\end{array}$ & 330 & $93 \%$ & $6 \times 59=354$ \\
$\begin{array}{l}\text { Probabilities } \\
\text { Rank ordered }\end{array}$ & 249 & $84 \%$ & $5 \times 59=295$ \\
$\begin{array}{l}\text { Utilities } \\
\begin{array}{l}\text { Rank ordered } \\
\text { Probabilities } \\
\text { nominal }\end{array}\end{array}$ & 89 & & \\
\hline & & $75 \%$ & $2 \times 59=118$ \\
total & 668 & $87 \%$ & $13 \times 59=767$ \\
\hline
\end{tabular}

Only two arguments with rank ordered utilities and nominal probabilities were presented, one where the Dominance rule should be used and one where we expected the Lexicographic rule as the warrant. In the case of the Dominance rule $90 \%$ of the participants specified a correct warrant. In the case of the Lexicographic rule, only $60 \%$ gave the correct answer which was surprising because the rule seemed obvious. The argument was formulated as follows. 
Strategy 1 leads to outcome A and B, A is positive. B is negative. Strategy 2 leads to outcome C and D. C is positive. D is negative. $\mathrm{A}$ and $\mathrm{D}$ are the most important outcomes in this situation.

While the argument seems to be clear, some respondents expressed their rule in such a way that made it seem incorrect or incomplete. The coding procedure required for a good answer that they mention that $\mathrm{A}$ and $\mathrm{D}$ are the most important outcomes and also that $\mathrm{A}$ is better than D. Some people did not include the importance sentence because this was mentioned in the task and they thought that they did not have to repeat this statement. We coded their answer as wrong even though they had chosen the right strategy.

The data indicated that all of the rules previously mentioned have been specified by the respondents but sometimes they specified an acceptable rule using less information than indicated in the description of the decision problem. Only in a very limited number of cases was an incorrect rule mentioned. For more details of this experiment, we refer to (Gallhofer, Saris and Schellekens, 1988).

Finally, concerning the third issue (the use of less information than indicated), we found that less educated people sometimes ignored the rank ordering and used more simple rules if they were sufficient to draw a conclusion. From these results we drew the following important conclusion: The rules specified above for the different types of arguments of politicians are warrants known to all people.

This proved to be true for the three types of arguments we have presented in Table 1. Only about the situation with ordering of utilities and probabilities not much can be said because this situation does not occur frequently enough. The reason is of course that this situation is too complicated to formulate clear arguments and to draw conclusions. Therefore, this type of arguments is only seldom used by decision makers to formulate their arguments. For all other arguments it is also clear that decision makers don't have to mention explicitly the decision rule or warrant because they are obvious for all people involved. 


\section{Generalisation across languages and decision makers}

Having shown that foreign policy decision makers in the Netherlands used relatively simple arguments to convince their colleagues of particular choices, we next wondered, whether decision makers in other countries and time periods behave similarly. Therefore, a study was carried out using minutes of speeches on the outbreaks of World War I and World War II and the Cuban Missile Crisis. For detailed information on the arguments, we refer to Gallhofer and Saris (1996, Part 1). In all cases the expected decision rules (warrants) predicted the choices made by the politicians.

Finally, a study of the arguments of American physicists concerning the use of nuclear bombs against Japan in 1945 was performed. The physicists' arguments can be found in Stoff et al. (1991). For details of the analyses, we refer to Saris and Gallhofer (2016). ${ }^{7}$ Compared to the politicians, the physicists used rank-ordered utilities more often. The reason for this, as Oppenheimer (Stoff, 149-150) suggests, is because there were positive short-term effects of dropping the bomb (fewer American lives lost) as well as negative long-term effects (the start of the arms race). To solve this problem, those who considered both aspects needed to evaluate the utilities to reach a decision. In those cases, the Lexicographic decision rule was used more frequently than we had seen before. In two cases the indicated choice could not be predicted with the warrants we had specified. In one case five different options were suggested and yet no decision rule could predict the final choice. In another case, a scientist specified an argument against the use of the bomb in a draft petition to the president. In that case, no known decision rule could predict the recommended choice. His colleagues also found that the argument was not properly formulated. Once he reformulated the argument, the appropriate decision rule could indeed derive his conclusion from the data.

${ }^{7}$ RECSM working paper 48 


\section{Conclusions}

We started this paper with the generally recognized problem that in general the consequences that have to be taken into account to make decisions are multi-dimensional and therefore not commensurable. Therefore, scholars have suggested that there is no logical way to derive the best action deductively from the data provided. We agreed that political decision problems are in general problems with many, very different consequences, which are difficult to compare. In this "warrant establishing" study we were able to find warrants that in almost $100 \%$ of the cases can derive the claim of the decision makers from the provided data. It is also important to mention that the warrants are not using the substantive information with respect to the consequences but only the information about the utilities and probabilities in the arguments. As required by Bermejo-Luque (2019), these warrants are general rules using these characteristics, independent of the specific substantive consequences specified.

This result is surprising because within each type of arguments, many plausible arguments would have been possible for which the hypothesized warrants would not have been able to predict the preferred strategy. Given the complexity of the decision problems in general, this suggests that decision makers reduce their arguments so much that the arguments satisfy the simple warrants we have specified and then the conclusion follows immediately from the data provided.

One solution is simplifying the decision problem to an argument of type I with nominal utilities and probabilities. Many of such arguments can be formulated but nearly none of them will present convincing arguments. Only when one formulates them in such a way that one possible action provides only positive results while the other action provides also negative results, then one can rely on the warrant, Simon's rule, to derive the preferred action. In that case, there is no doubt how one should choose.

A bit less simple is the reduction of the decision problem to a type 2 problem, allowing for different possible outcomes but using specifications of ordinal probabilities of the outcomes. Many of such arguments could be made but only using a very specific formulation of the argument, one can rely on the warrants, the Risk avoiding rules, to derive the preferred action. 
If one is forced to specify several different consequences for each possible action, then one proper warrant exists if one can show that for one action all outcomes are better than for all other possible actions. In that case the Dominance rule applies.

In general, one cannot formulate all decision problems in that way. Then one can solve the problem by saying that one consequence is so important that one should make the decision on the basis of these consequences for all options. This is the Lexicographic approach, which reduces the complex type 3 problem to a type 1 or type 2 problem.

A final solution in the case of a decision problem with many incomparable consequences, would be to say that the sum of the advantages and disadvantages of one option is larger than the sum of the advantages and disadvantages of the other options. In that case, the Addition of utilities rule is applied. This approach is of course in contradiction with the assumption that these consequences cannot be added but also this is a warrant which seems to be one of the tools in the toolbox of us to derive arguments for actions.

The decision the Dutch Government had to make, to occupy the seat of the republican government in the Dutch East Indies or not, was a complex problem with at least three incommensurable possible consequences of their possible actions, the military situation the Dutch East Indies, the international consequences and the national consequences. The Governor-General in the Dutch East Indies (Van Mook) has used all these approaches in his telegrams to convince the government of his preferred action. He seemed to be very capable to present his arguments in many different ways to try to convince the government of his preferred actions (Gallhofer and Saris 1986, pp. 219-225).

This approach of the speakers requires that the audience also knows these warrants and therefore knows which strategy has to be chosen. This was the second surprising result from our research. Even a random sample of the population made in $100 \%$ of the cases the same choice as proposed by the decision maker. In general, they were even able to indicate which argument they used to reach their conclusion.

As there was in these experiments, no reference to political decisions, this study seemed to suggest that the specified argumentation 
rules are the warrants for arguments in any type of context. This is an interesting issue for further research.

Given these two important results, the question arises what the warrants, we specified, represent. At the onset of this research, we thought that the warrants were the missing links needed to complete the argument to derive the claims from the data. However, our research rather suggests that these warrants are implicit rules of the arguments about decision problems, as mentioned by Hitchcock $(1985,91)$. We showed that the speakers and the audience intuitively know these warrants. Therefore, in general these rules, to derive the conclusions, don't have to be mentioned When people talk with each other, they don't have to explain the grammar to understand each other. The same seems to be true for the arguments concerning choices: the warrants don't require explanation because the speaker and the audience are already intuitively aware of them.

\subsection{Some limitations}

It should be clear that we don't want to suggest that people who argue in the ways, we have observed always make good decisions. It was surprising how much the decision makers simplify the problems to efficiently present their arguments. In doing so, information may have been lost that could have led to another, maybe better, decision. For example, imagine that a country must decide between using coal or nuclear energy for a new power plant. A politician could argue: "The use of coal leads to air pollution while nuclear energy does not produce air pollution and the risk of an accident is extremely small. Therefore, I suggest to build a nuclear plant." The conclusion follows from the data using as warrant the Risk avoiding rule. However, in this argument the air pollution and a possible accident are treated as two negative consequences. However, an accident like in Chernobyl or in Fukushima is not equivalent to the consequences of air pollution. One should also take into account additional consequences; but, in doing so, the decision problem becomes too complex for the simple warrants mentioned before. For such a decision a more elaborate procedure should be used as specified in mathematical decision theory (Keeney and Raiffa, 1976) or a simpler procedure as suggested by Saris, Neijens and De Ridder (1984) and Neijens (1987). 
A second limitation is that political decisions are usually made by groups. In this study we concentrated on the arguments made by a single person. In another study (Gallhofer and Saris, 1997) we discussed how groups, given the individual preferences, come to a joint decision.

The given approach to argumentation about decisions is restricted to the situation where one decision maker tries to convince other participants in the meeting to choose one strategy of two or more strategies. If no alternatives are formulated, as in a parliament (where often just one strategy is presented for evaluation), the argumentation takes another form and cannot be described by the concepts of decision theory. For this form of argumentation, we refer to Andone (2014), van Eemeren (2016), and Andone and Lomeli Hernandez (2019).

A similar argument should be made about the difference between our study and the work of Fairclough and Fairclough (2012) and Macagno and Walton (2018). There is a large difference in the setting for a politician if he/she has to talk about an action for a large public audience or if the same has to be done in the small group of experts. In the former case an introduction of the goal, the means, the values, effectiveness of the means and the side effects have to be mentioned. On the other hand, in a meeting of experts one does not have to talk about goals, since they are clear. The decision makers have to decide about the possible actions they could use and should use given the consequences of these actions. That are rather different settings which require rather different argumentations

Finally, this paper describes arguments for choices of actions, which is not the same as describing methods of decision making. There are two reasons to make this distinction. First, we cannot observe how people arrive at conclusions, as it is an internal process. What we can see is what they perceive to be a convincing argument for their preferred strategy. Therefore, this study was directed on informal implicit argumentation rules, warrants in Toulmin's terms, and not on decision rules. Due to our orientation on the mathematical decision theory, we used the term "decision rule" in our work, where "argumentation rule" would have been most appropriate. 


\section{Acknowledgments:}

We are very grateful for the useful comments we received from Corina Andone and two anonymous reviewers.

\section{References}

Andone, Corina. 2014. Pragmatic argumentation in European practices of political accountability. Argumentation 29(1): 1-18.

Andone, Corina, and José A.L Hernández. 2019. Scientific argumentation in policy-making. Journal of Argumentation in Context. 8(2): 195-213.

Becker, Gary. S. 1976. Economic approach to human behavior. IL: University of Chicago Press.

Bermejo-Luque, Lilian. 2004. Toulmin's model of argument and the question of relativism. Informal Logic 24(2): 169-181.

Bermejo-Luque Lilian. 2019. Appraisal of conductions. Informal Logic 39(2): 123-145.

Blair, J. Anthony. 2016 Advocacy vs. inquiry in small-group deliberations. In Argumentation and reasoned Action: Proceedings of the $1^{\text {st }}$ European conference on argumentation, Lisbon 2015, eds. Dima Mohammed and Marcin Lewiński, 53-68. London: College-Publications.

Drooglever, Pieter. J. and M.J. van Schouten, eds. 1981-1992. Officiële bescheiden betreffende de Nederlands Indonesische betrekkingen, 1945-1950. 1-17. The Hague: Nijhof.

van Eemeren, F. H. and R. Grootendorst. 1984. Speech acts in argumentative discussions, a theoretical model for the analysis of discussions directed towards solving conflicts of opinions. Berlin: De Gruyter.

van Eemeren, F. H., B. Garssen and H.L.M. Meuffels. 2009. Fallacies and judgements of reasonableness. Preliminary steps to pragma-dialectical effectiveness research. Argumentation 26(1): 33-53.

van Eemeren, F. H. 2016. Identifying argumentative patterns: A vital step in the development of pragma-dialectics. Argumentation 30(1): 1-23.

Erduran, Sibel, S. Simon and J. Osborne. 2004. TAPping into argumentation: Development in the application of Toulmin's argumentation pattern for studying science discourse. Science Education 88(6): 915-933.

Ericsson K. Anders, and H.A. Simon. 1984. Protocol analysis: Verbal reports as data. Cambridge, Ma: MIT Press.

Fairclough, Norman, and I. Fairclough 2012. Political discourse analysis. London: Routledge.

Fishburn, Peter. C. 1964. Decision and value theory. New York: Wiley. 
Gallhofer, Irmtraud N. and W.E. Saris. 1979. Strategy choices of foreign policy decision makers: The Netherlands 1914. Journal of Conflict Resolution 23(3): 425-445.

Gallhofer, Irmtraud N., W.E. Saris. and M. Schellekens. 1988. People's recognition of political decision arguments. In Acta Psycholica 68(13): 313-327.

Gallhofer, Irmtraud N., and W.E. Saris. 1996. Foreign policy decision making: A qualitative and quantitative analysis of political argumentation. Westport, CT: Praeger.

Gallhofer, Irmtraud N., and W.E. Saris. 1997. Collective choice processes: A qualitative and quantitative analysis of foreign policy decision making. Westport, CT: Praeger.

Garcia-Milla, Merce, S. Gilabert, S. Erduran and M. Felton. 2013. The effect of argumentative task goal on quality of argumentative discourse. Science Education 97(4): 497-523.

Hitchcock, David. 1985. Enthymematic arguments. Informal Logic VII (2-3): 83-91.

Keeney, Ralph L., and H. Raiffa. 1976. Decisions with multiple objectives: Preferences and value trade-offs, New York, NY: Wiley.

Kock, Christian. 2017. Deliberative rhetoric: Arguing about doing. Windsor Studies in Argumentation. 106-125.

Lewiński, Marcin. 2017. Practical argumentation as reasoned advocacy. Informal Logic 37(2): 85-113.

Macagno, Fabrizio, and D. Walton. 2018. Practical reasoning arguments: A modular approach. Argumention 32(4): 519-547.

Montgomery, Henry. 1989. From cognition to action: The search for dominance in decision making. In Process and structure of human decision making. Eds H. Montgomery and O. Svenson. 23-50. Chichester: Wiley.

Neijens Petrus. 1987. The choice questionnaire: Design and evaluation of an instrument for collecting informed opinions of a population. Amsterdam, Free University Press.

Perelman, Charles. 1959. Pragmatic arguments. Philosophy 34(1): 18-27.

Saris Willem E., P. Neijens and J.A. de Ridder. 1983. Kernenergie: Ja of nee: Een weloverwogen oordeel van de Nederlandse bevolking. Amsterdam: Stichting voor Sociometrisch Onderzoek

Saris Willem E., and I.N. Gallhofer. 1975. L'application d'un modèle de décision a des données historiques. Revue Française de science politique XXV(3): 473-501.

Savage, Leonard J. 1954. Foundations of statistics. New York: Wiley. Simon, Herbert A. 1957. Models of man: Social and rational. New York: Wiley. 
Stevens, Stanley S. 1946. On the theory of scales of measurement. Science, New Series 103(2684): 677-680.

Stoff, Michael B., J.F. Fanton and R.H. Williams. 1991. The Manhattan project: A documentary introduction to the atomic age. New York: McGraw-Hill Inc.

Toulmin, Stephen E. 1958. The uses of arguments. Cambridge: Cambridge University Press

Thrall, Robert M. 1954. Decision Processes. Eds C.H. Coombs and R.L. Davis. New York: Wiley. 